\title{
Dynamic Analysis of the Titanium Alloy Plate under Thermal-acoustic Loadings
}

\author{
Xuefeng ZOU ${ }^{1}$, Dingwen GUO ${ }^{1}$, Li ZHANG ${ }^{1}$ \\ ${ }^{1}$ AVIC Aircraft Strength Research Institute, Xi'an, Shaanxi, China
}

\begin{abstract}
Hypersonic vehicles structures suffer complex combined loadings generally. For the thin-walled structures and thermal protection systems of the aircraft, high temperature and intensity acoustic loadings are the significant factors that leading to their break. The object of this paper is typical simply supported titanium alloy plate, the finite element method was adopted to calculate the critical thermal buckling temperature the ordinal coupling method and Newmark method were adopted to calculate the thermalacoustic dynamic response. Based on the FEM analysis, the power spectrum densities (PSD) of center point was presented. Research results show that the thermal buckling of the typical simply supported titanium alloy plate occurs easily because of the low critical thermal buckling temperature, dynamic response of the thermal buckled plate suffering acoustic loads performs strong nonlinear characteristics and complex forms of exercise.
\end{abstract}

\section{Introduction}

With the fast development of aviation technology, advanced aircraft structures are exposed to combined loading environments, including mechanical, thermal, and acoustic loadings, such as thin-walled structures and thermal protection systems of aircraft, they suffer both high intensity acoustic loading and aerodynamic loading, while they are exposed to thermal environment [1]. The effects for the structures caused by combined loadings are more seriously than that simply super imposed by the single load [2]. The dynamic response research of the aircraft under the combined loads has become essential for the aircraft structure design.

The dynamic response research of the aircraft structures developed with advances in aviation technology. Early in the last century, the thermal buckling analysis and thermal-acoustic response analysis were developed abroad; early research object is single freedom degree beam. Chen and Mei, et al [3], analyzed dynamic response of the beams underling thermalacoustic loadings using FEM and Newmark method; $\mathrm{Ng}$, et al [4,5], derived the single-mode equations using the Von Karman equation and Galerkin method, they also analyzed the nonlinear response of the flat and bent plates underling thermal-acoustic loadings by relatively experiment, including the basic dynamic response features and the snap-through motions; Vaicaitis, et al [6], analyzed the nonlinear response of the aircraft structure under random load using Montecarlo method.

In this paper, the object is typical simply supported titanium alloy plate of the aircraft structure. The first order critical buckling temperature of the plate is obtained by Eigenvalue analysis, and the thermal-acoustic response of the plate is calculated by the FEM. A preliminary discussion on the thermal-acoustic response mechanism is analyzed to provide reference for the acoustic fatigue test and structure design of the aircraft in thermal-acoustic environment.

\section{Motion equations of the thin-walled plate under thermal-acoustic loadings}

Generally, the nonlinear vibration for thermal bucked structure is considered to calculate the thermal-acoustic response [7-11]. The response of the post thermal buckling plate can be seen as a shell problem, as the FEM is used to solve the shell problem.

The following equations are derived using plane triangle element, considering the initial stress and temperature stress, internal force $\{\mathrm{N}\}$, bending moment and torque $\{M\}$ are respectively:

$$
\begin{gathered}
\{N\}=[C]\{e\}+\left\{N_{0}\right\}-\left\{N_{\Delta T}\right\} \\
\{M\}=[D]\{k\}+\left\{M_{0}\right\}
\end{gathered}
$$

Where $\left\{N_{\Delta T}\right\}$ is the internal force caused by temperature, $[C] 、[D]$ is Elastic matrix, $\left\{N_{0}\right\}$ is initial force, $\left\{M_{0}\right\}$ is torque. 


$$
\begin{gathered}
{[C]=\frac{E h}{1-\mu^{2}}\left[\begin{array}{ccc}
1 & \mu & 0 \\
\mu & 1 & 0 \\
0 & 0 & \frac{1-\mu}{2}
\end{array}\right]} \\
{[D]=\frac{E h}{12\left(1-\mu^{2}\right)}\left[\begin{array}{ccc}
1 & \mu & 0 \\
\mu & 1 & 0 \\
0 & 0 & \frac{1-\mu}{2}
\end{array}\right]}
\end{gathered}
$$

The internal force caused by the change of temperature is derived as follow:

$$
\left\{N_{\Delta T}\right\}=\frac{E \alpha h \Delta T(x, y)}{1-\mu}\left\{\begin{array}{l}
1 \\
1 \\
0
\end{array}\right\}
$$

The internal force $\left\{N_{0}\right\}$ and bending moment $\left\{M_{0}\right\}$ caused by the initial force are derived as follows:

$$
\left\{N_{0}, M_{0}\right\}=\int_{-h / 2}^{h / 2}(1, z)\left\{\sigma_{0}\right\} d z
$$

According to the principle of virtual work, the Eq. (7) to Eq. (9) is obtained:

$$
\begin{gathered}
\delta W=\delta W_{\mathrm{int}}-\delta W_{\text {ext }}=0 \\
\delta W_{\mathrm{int}}=\int_{A}\left(\{\delta e\}^{T}\{N\}+\{\delta k\}^{T}\{M\}\right) d A \\
\delta W_{\text {ext }}=\int_{A} \delta W(-p h \ddot{W}-C \dot{W}+p) d A
\end{gathered}
$$

Where $\delta W_{\text {int }}$ and $\delta W_{\text {ext }}$ are internal virtual work and external virtual work respectively, the motion equation of the system underling combined thermal loadings and acoustic loadings are obtained by Eq. (7) to Eq. (9):

$$
\{\Psi(Q, \dot{Q}, \ddot{Q})\}=\left[K+\frac{1}{2} N 1+\frac{1}{3} N 2\right]\{Q\}+[C]\{\dot{Q}\}+[M]\{\ddot{Q}\}-\{P\}=0
$$

Where $[K]$ is the linear stiffness matrix consist of the terms caused by initial stress, initial displacement and thermal stress, also consist of term caused by the coupling between membrane and bending, $[N 1]$ is the first nonlinear stiffness matrix consist of the influence of the initial displacements, [N2] is the second stiffness matrix, $\{P\}$ is generalized external load vector consist of acoustic load and additional load caused by the initial displacement temperature.

\section{The finite element model}

The model is a titanium alloy plate that measured $330 \mathrm{~mm} \times 395 \mathrm{~mm} \times 1.5 \mathrm{~mm}(a \times b \times h)$. The material of the model shown in Figure.1 is Ti-Al-4V (TC4); its main physical properties are given in the Table1.

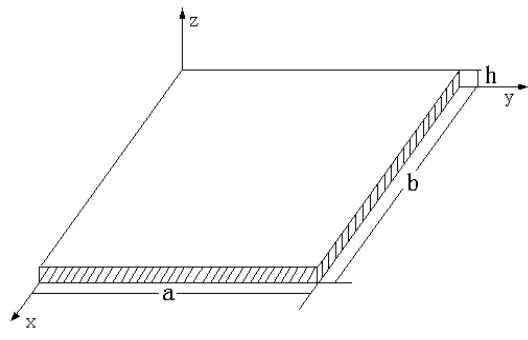

Figure 1.Geometry dimensions of the model

Table 1.Physical characteristics of TC4 (Ti-Al-4V)

\begin{tabular}{|c|c|c|c|}
\hline$\rho /\left(\mathrm{kgm}^{-3}\right)$ & $\alpha /\left({ }^{\circ} \mathrm{C}^{-1}\right)$ & $E /(\mathrm{GPa})$ & $\mu$ \\
\hline 4440 & $9.1 \mathrm{e}-6$ & 123.0 & 0.3 \\
\hline
\end{tabular}

Thermal acoustic response analysis of the plate is a coupling problem, and analysis of coupled field eventually can be classified into two different methods: sequential coupling and direct coupling method [12-13].

Steady-state thermal analysis module, thermal buckling analysis module, mode analysis module and random vibration module of the ANSYS software are adopted for solving the thermal-acoustic response problem of the titanium alloy plate, using the direct coupling method, the detail process is shown in Figure.2.

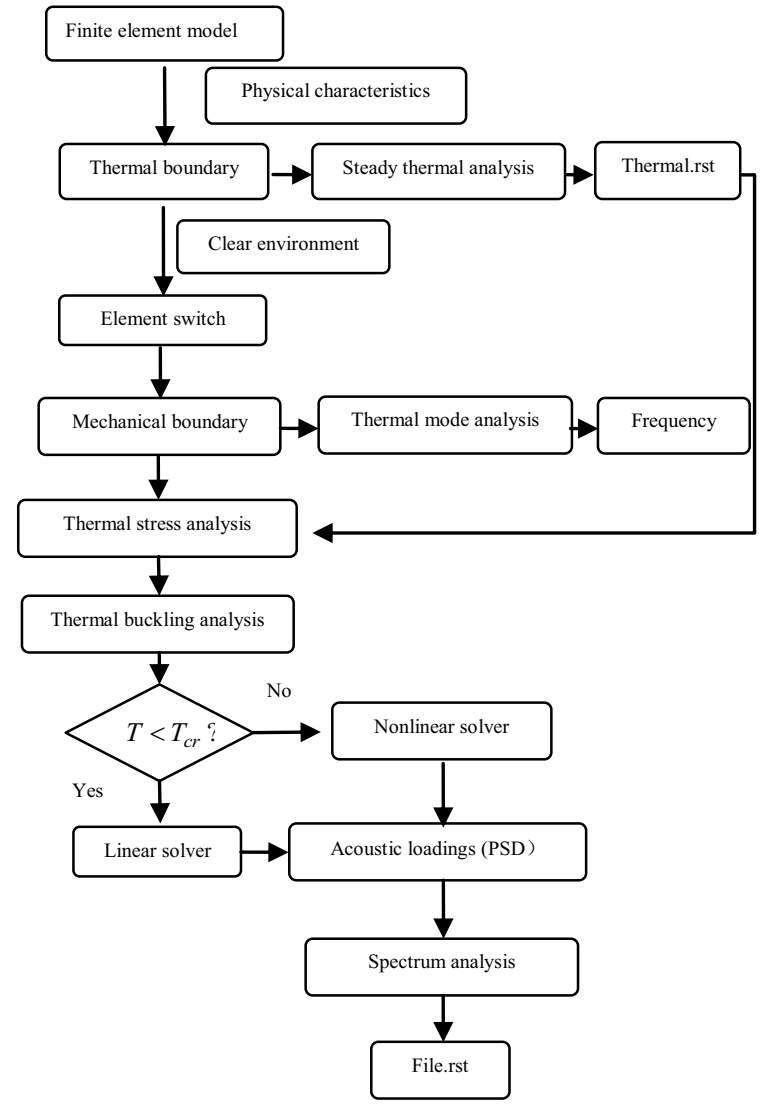

Figure 2.The analysis process for thermal acoustic coupling problem 


\section{Thermal-acoustic coupling analysis}

The titanium alloy plate is simply supported at four edges, the initial temperature and the reference temperature are $20^{\circ} \mathrm{C}$, and a uniform temperature field of $50^{\circ} \mathrm{C}$ is applied to the plate. For the simply supported plate structure of steady temperature field, the first order critical buckling temperature is calculated by the following theoretical calculation formula:

$$
T_{C}=\frac{\pi^{2} h^{2}}{12(1+\mu) \alpha b^{2}}\left(1+\frac{b^{2}}{a^{2}}\right)
$$

Where $\mathrm{a}, \mathrm{b}$ and $\mathrm{h}$ are the length, width and thickness of the plate respectively, $\mu$ is the poisson's ratio, $\alpha$ is the coefficient of thermal expansion. The first order critical buckling temperature of the plate $T_{C}=22.36^{\circ} \mathrm{C}$ is obtained through the formula (11); Set the buckling coefficient [14]

$$
\mathrm{S}=\frac{\mathrm{T}-\mathrm{T}_{\text {ref }}}{T_{c r}-T_{r e f}}
$$

Where $T_{\text {ref }}$ is the reference temperature, the value of $T_{\text {ref }}$ is $20^{\circ} \mathrm{C}$. It is obviously that the plate is in the pre-buckling state while $0<S<1$, and the plate is in the post buckling state while $S>1$.

The first five order natural frequencies of the titanium alloy plate in different buckling coefficients $\mathrm{S}=0.8 、 \mathrm{~S}=1.0 、 \mathrm{~S}=1.6$ are calculated separately, the results are shown in Table.2.

Table 2.The first five order natural frequencies of the titanium alloy plate

\begin{tabular}{|l|l|l|l|l|l|}
\hline $\mathrm{S}$ & $f_{1} /(\mathrm{Hz})$ & $f_{2} /(\mathrm{Hz})$ & $f_{3} /(\mathrm{Hz})$ & $f_{4} /(\mathrm{Hz})$ & $f_{5} /(\mathrm{Hz})$ \\
\hline 0.0 & 59.41 & 132.71 & 164.47 & 237.72 & 255.03 \\
\hline 0.6 & 37.57 & 113.50 & 145.56 & 219.18 & 236.55 \\
\hline 1.0 & 0.00 & 98.63 & 131.46 & 205.89 & 223.38 \\
\hline 1.6 & 70.00 & 106.87 & 184.18 & 202.02 & 288.53 \\
\hline
\end{tabular}

It can be seen from Table. 3 that natural frequency of the plate drops with the increase of temperature, the structure is in a critical buckling state and prone to snap-through when the first order natural frequency drops to zero, the structure enters the post bucked state with the continue increase of the temperature, natural frequency increases until the next order critical buckling state because of the stress stiffness effect.

Noise is in essence a random excitation, spectrum analysis can be used to simulate and solve the random vibration problem, spectrum analyze module of the ANSYS software provides different types of response spectra, including displacement spectrum, velocity spectrum, acceleration spectrum, pressure spectrum and power spectrum. These loads spectrum can be applied to both finite element models can also be directly applied to the related geometry, the acoustic loads can be applied to the structure according to its pressure power spectral density (PSD). A band-limited Gaussian white noise random pressure loading in the frequency range of $0 \sim 1000 \mathrm{~Hz}$ are applied to the upper surface of the titanium alloy plate, the plate is subjected to a spatially uniform thermal loading having zero through-the-thickness variation in addition. The power spectral density of the Gaussian white noise can be calculated by following formula:

$$
\operatorname{PSD}(\mathrm{f})=\frac{\mathrm{P}_{0}^{2}}{\Delta f} 10^{\frac{L}{10}}
$$

where static pressure $\mathrm{P}_{0}$ is $2 \times 10^{-5}$ pa, $\Delta f$ is band width, $\mathrm{L}$ is overall pressure level, for the Gaussian white noise with an overall sound pressure level of $160 \mathrm{~dB}$ in the frequency range $0 \sim 100 \mathrm{~Hz}$, the calculated result for the power spectral density is $4000 \mathrm{~Pa}^{2} / \mathrm{Hz}$, it is shown in Figure.3.

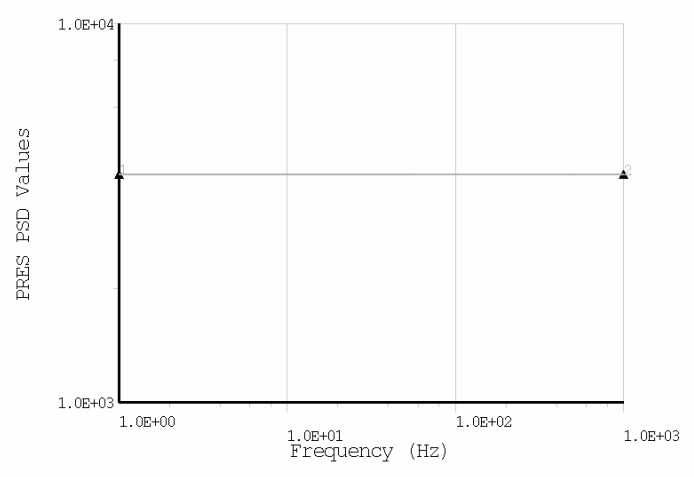

Figure 3.PSD of the acoustic load

Based on the thermal stress analysis and mode analysis of the titanium alloy plate, random vibration analysis using spectrum analysis method is conducted, and the thermalacoustic response characteristics of the titanium alloy plate are calculated, the thermal-acoustic response in different buckling coefficients are considered: $S=0,0.6,1.0$ and 1.6.The maximum principal stresses in different buckling coefficients are listed in Table. 3 .

Table 3.The maximum principal stresses in different buckling coefficients

\begin{tabular}{|c|c|c|}
\hline OASPL/(dB) & $\begin{array}{l}\text { buckling } \\
\text { coefficients }(\mathrm{S})\end{array}$ & $\begin{array}{l}\text { The maximum principal } \\
\text { stress/(MPa) }\end{array}$ \\
\hline 160 & $\mathrm{~S}=0.0$ & 84.8 \\
\hline 160 & $\mathrm{~S}=0.6$ & 125.0 \\
\hline 160 & $\mathrm{~S}=1.0$ & 264.0 \\
\hline 160 & $\mathrm{~S}=1.6$ & 19.8 \\
\hline
\end{tabular}

From the Table 2, it is seen that the maximum principal stress of the plate varies obviously with the value of the buckling coefficient. For the pre-buckling plate, the node has the maximum principal stress locates in the center of the plate. The maximum principle stress increases with the rise of the temperature. The buckling of the plate occurs when the temperature rise to the critical point, the maximum principal stress increases rapidly at present. Mode shapes of the plate changes when it gets into the post buckling state with the 
continue rise of the temperature, location and value of the maximum principal stress are all changed, the maximum principal stress contours before and after buckling are shown in Figure. 4 and Figure. 5 respectively.

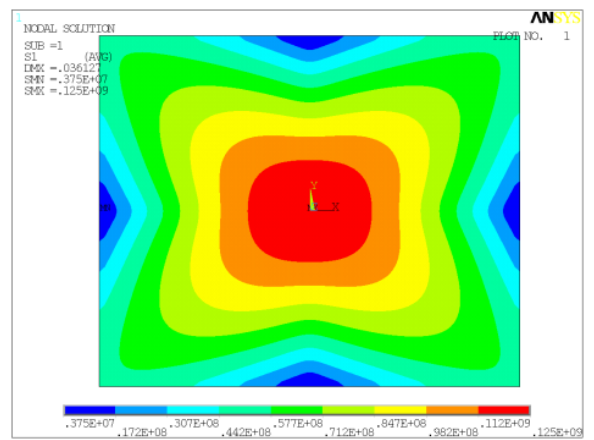

Figure 4. The maximum principal stress $(\mathrm{S}=0.6, \mathrm{SPL}=160 \mathrm{~dB})$

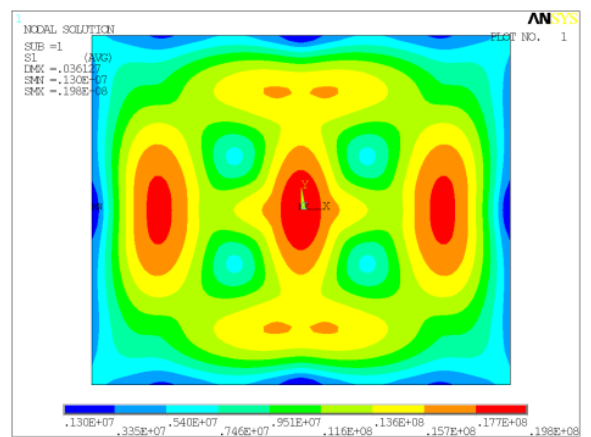

Figure 5. The maximum principal stress $(\mathrm{S}=1.6, \mathrm{SPL}=160 \mathrm{~dB})$

The time history curves of plate midpoint placement of $\mathrm{Z}$ direction before and after buckling are shown in Figure. 4 and Figure. 5 respectively, it is seen that the plate vibrates around the initial equilibrium position before buckling, but the amplitude and the in-plane stress increase obviously compared with the vibration at room temperature. Snap-through due to geometric nonlinearity occurs when the temperature is higher than the critical buckling temperature [15]. The structure has two equilibrium positions while OASPL $=160 \mathrm{~dB}$, the plate snaps around between the two equilibrium positions and RMS of the displacement and stress increase obviously at present. The structure is prone to damage because of the Inversion of stresses due to snap-through.

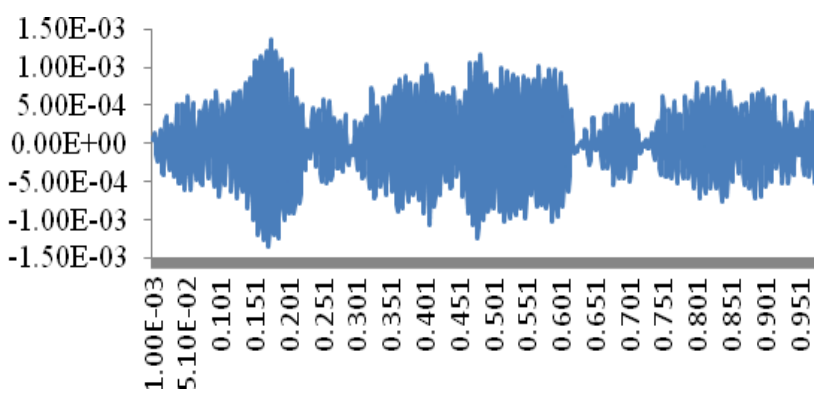

Figure 6.Time history curve of plate midpoint placement of $\mathrm{Z}$ direction $(\mathrm{S}=0.6, \mathrm{SPL}=160 \mathrm{~dB})$

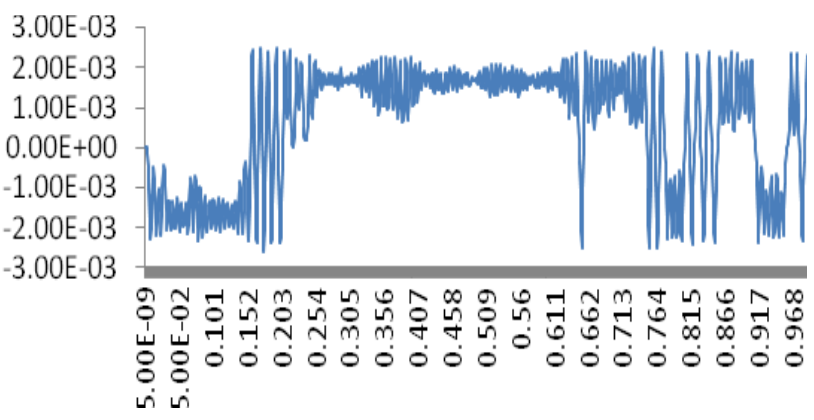

Figure 7.Time history curve of plate midpoint placement of $\mathrm{Z}$ direction $(\mathrm{S}=1.6, \mathrm{SPL}=160 \mathrm{~dB})$

\section{Conclusions}

In this paper, thermal buckling analysis, thermal mode analysis and thermal-acoustic response analysis of the titanium alloy plate based on the thermal-acoustic coupling model are conducted, the following conclusion is summarized: For the plate underling thermal-acoustic loadings, the response characteristics is more complex, it is mainly reflected in following aspects: the stress level of the plate increases with rise of the temperature before buckling ; the stress level has a sharp increase when the temperature rises to the critical buckling point, the structure is prone to fatigue failure at present; the stress level has a obvious drop when the plate entering the post buckling state, then the stress level re enter the rising phase as the rise of temperature.

\section{References}

1. WU Zhen-qiang, REN Fang, ZHANG Wei. Research advances in thermal-acoustic testing of aero craft structures[J]. Missiles and Space Vehicles, 2: 24-30, 2010.

2. Mei C. Nonlinear random response of composite panels in an elevated thermal environment[J]. Air Force Research Laboratory AFRL-VA-WP-T R-2000-3049, WPAFB, OH, 2000.

3. Chen R X, Mei C. Finite element nonlinear random response of beams to acoustic and thermal loads applied 
simultaneously. The Proceedings of the 34th AIAA/ASME/ASCE/AHS/ASC Structures, Structural Dynamic and Materials Conference, 1993.

4. $\mathrm{Ng} \mathrm{C} \mathrm{F,} \mathrm{Clevenson} \mathrm{S} \mathrm{A.} \mathrm{High-intensity} \mathrm{acoustic} \mathrm{tests} \mathrm{of} \mathrm{a}$ thermally stressed plate. Journal of aircraft, 28 (4): 275281, 1991.

5. $\mathrm{Ng} \mathrm{C} \mathrm{F,} \mathrm{Wentz} \mathrm{K} \mathrm{R.} \mathrm{The} \mathrm{prediction} \mathrm{and} \mathrm{measurement} \mathrm{of}$ thermo-acoustic response of plate structures. The Proceedings of the 31st AIAA/ASME/ASCE/AHS/ASC Structures, Structural Dynamics and Materials Conference, 1990.

6. Vaicaitis R. Nonlinear response and sonic fatigue of national aerospace space plane surface plates. Journal of Aircraft, 31(1):10-18, 1994.

7. SHA Yundong, WEI Jing, GAO Zhijun. Nonlinear response and fatigue life prediction of thin-walled structures under thermo-acoustic loadings [J] .Applied Mechanics and Materials. 157-158:1204-1211, 2012.

8. Sha Y D, Gao Z J, Xu F. Influence of thermal loading on the dynamic response of thin-walled structure under thermo-acoustic loading[J]. Applied Mechanics and Materials, 2011,105-107:220-226

9. Sha Y D,Xu F, Gao Z J. Nonlinear response of carboncarbon composite panels subjected to thermal-acoustic loadings[J]. Journal of Applied Mechanics and Materials,2011,117-119:876-881.
10. Rizzi, S A, Przekop, A. The effect of basics selection on thermal-acoustic random response prediction using nonlinear modal simulation. The proceedings of the 45th AIAA/ASME/ASCE/AHS/ASC Structures, Structure Dynamics and Material Conference, 2004.

11. Tzou H S, Zhou Y H. Nonlinear piezo thermal elasticity and multi-field actuation, part2; Control of nonlinear deflection buckling and dynamics[J]. Transaction of the ASME:The Journal and Acoustics, 1997,119:382-389.

12. Charles C. Gray. Chuh Mei. Finite element analysis of thermal post-buckling and vibrations of thermally buckled composite[J]. (30):188-190, 2008.

13. Rizzi, S.A. and Przekop, A. Estimation of sonic fatigue by reduced-order finite element based analysis, structure Dynamics: Recent Advances, Proceedings of the 9th International Conference, The Institute of Sound and Vibration Research, University of Southampton[C].UK, 2006, M. J. Brennan, B. R. Mace, J. M. Muggleton, B. A. Petersson, K. D. Murphy, S. A. Rizzi, and R. Shen(ed.)

14. Tzou H S, Zhou Y H. Nonlinear piezo thermal elasticity and multi-field actuation, Part2: Control of nonlinear defection buckling and dynamics [J]. Transaction of the ASME: The Journal and Acoustics, 119: 382-389, 1997.

15. Steven Goley G, Brian J. Zappia. Effect of loading on the snap-through response of a post-buckled beam[R]. AIAA. 2008-2234. 